\title{
Biochemical Characterization of Citrobacter diversus (Burkey) Werkman and Gillen and Designation of the Neotype Strain
}

\author{
W. H. EWING and B. R. DAVIS \\ Center for Disease Control, Atlanta, Georgia 30333
}

\begin{abstract}
The biochemical characteristics of 137 strains of Citrobacter diversus (Burkey) Werkman and Gillen were determined, and the resulting data are summarized. Members of this species produced indole and ornithine decarboxylase and fermented adonitol but failed to grow in KCN medium. Detectable amounts of hydrogen sulfide were not produced in triple sugar-iron-agar medium but were formed by some strains in peptone-iron-agar. The nomenclature and taxonomic position of these bacteria are discussed, and information that should be helpful for their differentiation from Citrobacter freundii and Enterobacter cloacae is included. Strain 3613-63 (ATCC 27156) is designated as the neotype strain and is described herein.
\end{abstract}

Werkman and Gillen (32) proposed the generic name Citrobacter for the "citratepositive, coli-aerogenes intermediates", from a collection of fifteen strains, these investigators described seven species. Citrobacter Freundii (sic) Braak was designated as the type species of the new genus. A review of the literature [e.g., see Vaughn and Levine (31)] indicated that some, but by no means all, of the so-called intermediate bacteria belonged to the genus Citrobacter. Tittsler and Sandholzer (30) and Carpenter and Fulton (7) suggested that "Escherichia-Aerobacter intermediate" strains, which did not produce acetylmethylcarbinol but utilized sodium citrate as a sole source of carbon, should be placed in the genus Escherichia. This suggestion, rather than that of Werkman and Gillen (32), was followed in the 1939, 1948, and 1957 editions of Bergey's Manual (2-4). Vaughn and Levine (31) delineated two divisions among the "intermediate" bacteria studied. Members of the first of these produced hydrogen sulfide, whereas constituents of the second did not. These investigators stated that the bacteria that produced hydrogen sulfide might be recognized as Escherichia freundii (Braak) Yale and that the hydrogen sulfide-negative microorganisms might be recognized as Escherichia intermedium (Werkman and Gillen) comb. nov. The latter species was recognized in the 1948 edition of Bergey's Manual. Ewing and Edwards
$(15,16)$ and Ewing $(11,12)$ considered members of the genus Citrobacter to be more closely related to the genera Salmonella and Arizona than to either Escherichia or Aerobacter (now Enterobacter).

As presently constituted, the genus Citrobacter is composed of similar bacteria that have been described under a variety of designations in addition to those already mentioned. For example, the microorganism called Salmonella ballerup (22), " $S$. coli" 1 to 4 (21), and Salmonella hormaechei [Monteverde (1944) cited by Bruner et al., (5)] originally were classified as salmonellae because of antigenic relationships and were included in the antigenic schema for those bacteria. Later, they were removed from the antigenic schema for Salmonella on the basis of their biochemical reactions [e.g., see Harhoff (20); Bruner et al. (5)]. These microorganisms now are considered to be $C$. freundii. Strains that closely resembled the 14011 biotype of Stuart et al. (29) were found to be members of the Bethesda group characterized by Barnes and Cherry (1) and so named by Edwards et al. (10) and Moran and Bruner (28). West and Edwards (33) investigated 585 strains of Ballerup and Bethesda bacteria, combined these two into the so-called Bethesda-Ballerup group, and directed attention to the close biochemical relationships of members of the combined group and those of cultures of $E$. freundii. 
Davis and Ewing (8) reviewed the pertinent literature pertaining to the biochemical reactions of $C$. freundii and tabulated data that lent itself to such treatment (see tables 1 to 7 in reference 8 ). It was notable that with few exceptions, strains that fermented adonitol were excluded from the species $C$. freundii and from the genus Citrobacter by the investigators whose works were reviewed or cited in the preceding paragraphs. However, strains that belonged to two of the species (Citrobacter decolorans and Citrobacter diversum) of Werkman and Gillen (32) were characterized as fermenters of adonitol. In addition, one of the strains studied by Tittsler and Sandholzer (30) and four of those named $E$. intermedium by Vaughn and Levine (31) utilized that substrate.

Since $C$. freundii and $C$. intermedium of Werkman and Gillen (32) failed to ferment adonitol, and since the majority of investigators (v. sup.) excluded strains that fermented adonitol from the genus Citrobacter and from C. freundii, Davis and Ewing (8) followed this established precedent. One of the characteristics of the 582 isolants of $C$. freundii reported upon was failure to form acid from adonitol. It was mentioned, however, that a small collection of strains that were adonitolpositive were under investigation.

Leclerc and Buttiaux (24) reported the characteristics of 203 isolants of Enterobacteriaceae which failed to form hydrogen sulfide and which were said to be close to Citrobacter. According to these investigators, lysine was decarboxylated by 90 of the strains (method not given). Except for this aberrancy, the strains appeared to represent a hydrogen sulfide-negative biotype of $C$. freundii similar to that of the 93 strains mentioned by Davis and Ewing (8). None of the investigators cited in the foregoing paragraphs reported decarboxylation of lysine by any isolate of Citrobacter, and the authors never have seen a strain that could be called Citrobacter that decarboxylated lysine in M $\phi$ ller's medium (final readings 4 days). However, it is known (27; unpublished data of author) that an occasional strain may produce a weak reaction in lysine medium if kept beyond the recommended period of observation.

Macierewicz (26) recorded the biochemical reactions of 27 strains that were similar to the 93 hydrogen sulfide-negative strains mentioned by Davis and Ewing (8), except that the percentage of the late liquefiers of gelatin was unusually high among the strains studied by Macierewicz. She (26) proposed a new, pro- visional genus (Padlewskia) for these bacteria. As far as the authors have been able to determine, a species was not named or described in the proposed genus.

In 1970, Frederiksen (19) described a collection of $\mathbf{3 0}$ strains and proposed the name Citrobacter koseri for them. Hydrogen sulfide production by these isolates was characterized as weak, indole was produced, and adonitol was fermented. Except for weak production of hydrogen sulfide, the reactions recorded were similar to those of the adonitol fermenters mentioned by Davis and Ewing (8) and described in more detail herein.

As a result of their investigations of 108 isolants, Young et al. (34) described a new genus, Levinea, and two species, L. malonatica and $L$. amalonatica. The essential difference between these two species appeared to be utilization of sodium malonate. V. M. Young (Baltimore Cancer Research Center, National Cancer Institute, Baltimore, Md. 21211) kindly supplied the authors with eight strains representative of each of the species. The bacteria described as $L$. malonatica by Young et al. (34) were similar to the adonitol-positive strains mentioned by Davis and Ewing (8).

The names proposed by Frederiksen (19) and Young et al. (34) were validly published and legitimate, in the authors' opinion. However, the species names proposed by Werkman and Gillen (32) also were validly published and legitimate, and they have priority.

Davis and Ewing (9) reported the characteristics of 616 strains of C. freundii [127 of which failed to produce hydrogen sulfide in triple sugar-iron (TSI)-agar in the usual period of incubation] and compared the resulting data with those obtained in the present work.

\section{MATERIALS AND METHODS}

The 137 strains reported upon were submitted to the Center for Disease Control for identification between January 1962 and December 1970. Some of these adonitol-positive forms were mentioned by Davis and Ewing (8). (The authors now regard these microorganisms as a second species of Citrobacter, $C$. diversus.) If strains of this sort were received prior to 1962 , they were not recognized for what they were. The majority of the 137 isolates were recovered from specimens of human origin [see Davis and Ewing, (9)] and constituted about $14 \%$ of the total number of strains of Citrobacter received during the abovementioned period.

The biochemical reactions of 113 of the 137 isolants were determined by means of a rather large 
TABLE 1. Summary of the biochemical reactions of Citrobacter diversus and its neotype strain

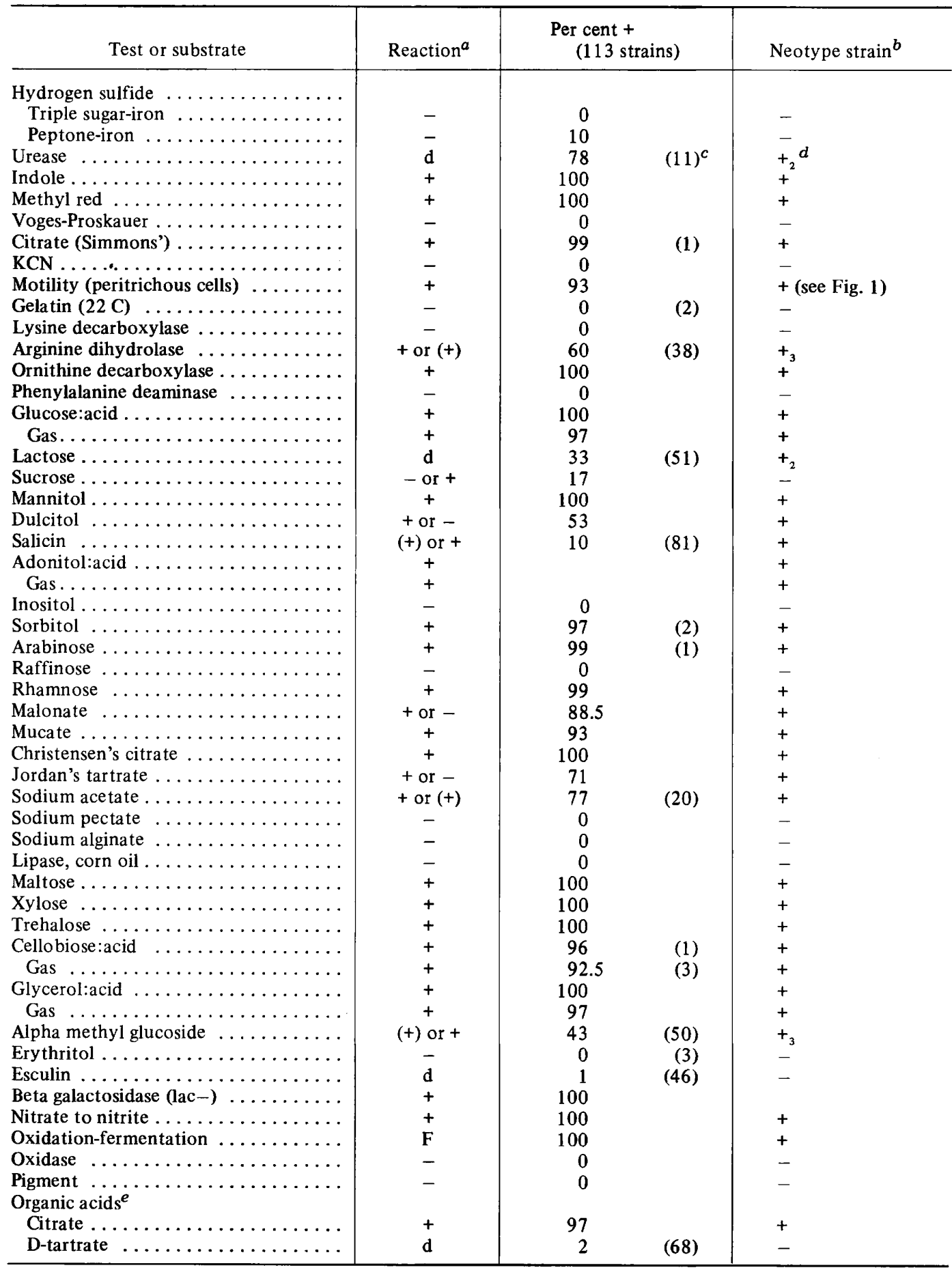

${ }^{a}$ Symbols:,$+ 90 \%$ or more positive within 1 or 2 days of incubation; (+), positive reaction after 3 or more days (decarboxylase tests: 3 or 4 days); - , no reaction $(90 \%$ or more); + or - , majority of strains positive, some cultures negative; - or + , majority of cultures negative, some strains positive; $(+)$ or + , majority of reactions delayed, some occur within 1 or 2 days; d, different reactions: $+,(+),-$.

$b$ Strain no. 3613-63 (ATCC 27156).

$c$ Figures in parentheses indicate percentage of delayed reactions ( 3 or more days).

$d$ Subscript numbers indicate day on which reaction occurred.

e Method of Kauffmann and Petersen (23). 
TABLE 2. Differentiation of hydrogen sulfide-positive and hydrogen sulfide-negative strains of Citrobacter freundii from $C$. diversus

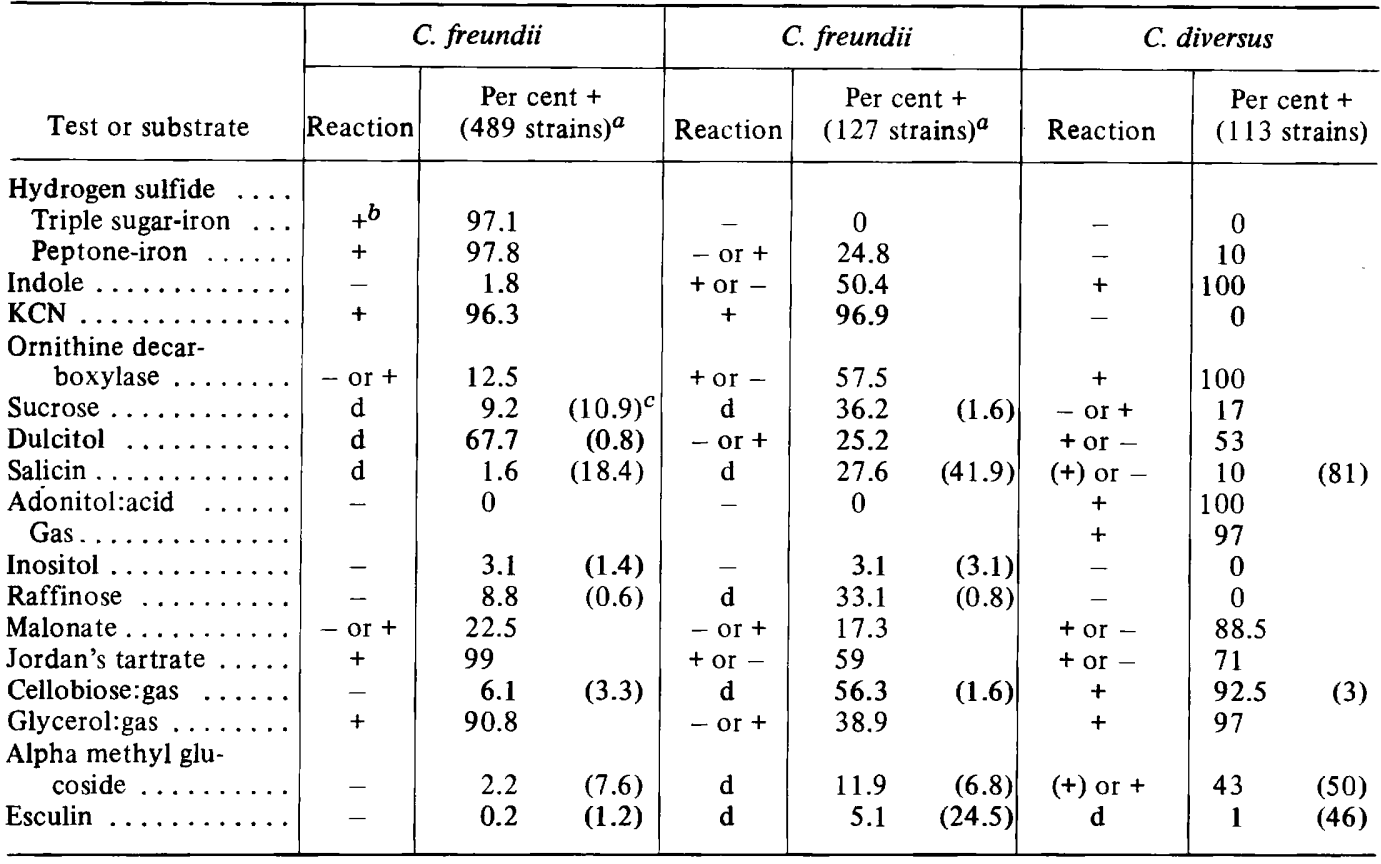

${ }^{a}$ From Davis and Ewing (9).

b See Table 1, footnote $a$, for explanation of symbols.

$c$ Numbers in parentheses indicate percentage of delayed reactions ( 3 or more days).

TABLE 3. Differentiation of hydrogen sulfide-negative, indole-positive strains of Citrobacter freundii from $C$. diversus

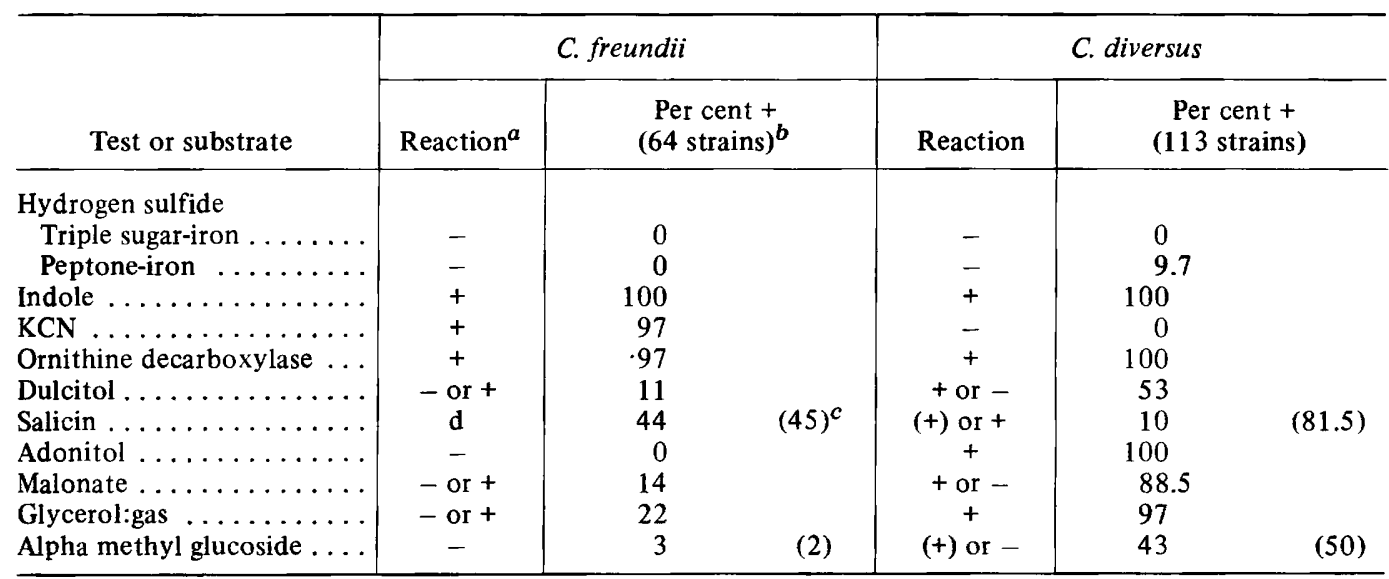

${ }^{a}$ See Table 1, footnote $a$, for explanation of symbols.

$b$ Based on a portion of the 127 strains of the hydrogen sulfide-negative biotype recorded in Table 2 .

$c$ Numbers in parentheses indicate percentage of delayed reactions ( 3 or more days).

number of tests and substrates. The remaining 24 were subjected to a limited number of tests, i.e., those commonly used (13). The methods employed were the same as those described by Ewing $(13,14)$, Ewing and Davis (17), and Ewing and Edwards (in press). Unless otherwise indicated, the temperature of incubation was 35 to $37 \mathrm{C}$.

\section{RESULTS}

The results of examination of the biochemical reactions given by 113 strains of Citrobacter that fermented adonitol but failed to grow in $\mathrm{KCN}$ medium are summarized in 
TABLE 4. Differentiation of Citrobacter diversus and Enterobacter cloacae

\begin{tabular}{|c|c|c|c|c|c|c|}
\hline \multirow[b]{2}{*}{ Test or substrate } & \multicolumn{3}{|c|}{ C. diversus } & \multicolumn{3}{|c|}{ E. cloacae $e^{a}$} \\
\hline & Reaction $^{b}$ & $\begin{array}{c}\mathrm{Pe} \\
11\end{array}$ & & Reaction & $\begin{array}{l}\text { Per } \\
200\end{array}$ & \\
\hline Indole $\ldots \ldots \ldots \ldots \ldots$ & + & 100 & & - & 0 & \\
\hline Methyl red $\ldots \ldots \ldots \ldots$ & + & 100 & & - & 0 & \\
\hline Voges-Proskauer . . . . . . & - & 0 & & + & 100 & \\
\hline $\mathrm{KCN} \ldots \ldots \ldots \ldots \ldots$ & - & 0 & & + & 98 & \\
\hline Gelatin $(22 \mathrm{C}) \ldots \ldots \ldots$ & - & 0 & $(2)^{c}$ & $(+)$ & 1 & $(96)$ \\
\hline 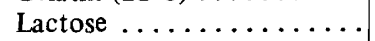 & $\mathrm{d}$ & 33 & $(51)$ & + & 93.5 & $(5.5)$ \\
\hline Sucrose $\ldots \ldots \ldots \ldots \ldots$ & - or + & 17 & & + & 96.5 & $(0.5)$ \\
\hline Dulcitol $\ldots \ldots \ldots \ldots \ldots$ & + or - & 53 & & - or + & 13 & \\
\hline Salicin . . . . . . . . . & (3) or + & 10 & $(81)$ & + or $(+)$ & 76 & $(18.5)$ \\
\hline Adonitol $\ldots \ldots \ldots \ldots$ & + & 100 & & - or + & 28.5 & \\
\hline Inositol:acid ....... & - & 0 & & $\mathrm{~d}$ & 22 & (12) \\
\hline Gas ........... & - & 0 & & - & 45 & \\
\hline Raffinose $\ldots \ldots \ldots$ & - & 0 & & + & 97 & \\
\hline Jordan's tartrate ........ & + or - & 71 & & - or + & 27.4 & \\
\hline Glycerol:acid $\ldots \ldots \ldots \ldots$ & + & 100 & & $\mathrm{~d}$ & 43 & (45) \\
\hline Gas $\ldots \ldots \ldots \ldots \ldots$ & + & 97 & & $\mathrm{~d}$ & 5.5 & (16) \\
\hline Alpha methyl glucoside .... & $(+)$ or + & 43 & $(50)$ & $(+)$ or + & 84.1 & (12.8) \\
\hline Esculin $\ldots \ldots \ldots \ldots \ldots$ & $\mathrm{d}$ & 1 & (46) & + or - & 29.5 & \\
\hline
\end{tabular}

${ }^{a}$ From Fife et al. (18), revised.

${ }^{b}$ See Table 1, footnote $a$, for explanation of symbols.

${ }^{c}$ Numbers in parentheses indicate percentage of delayed reactions ( 3 or more days).

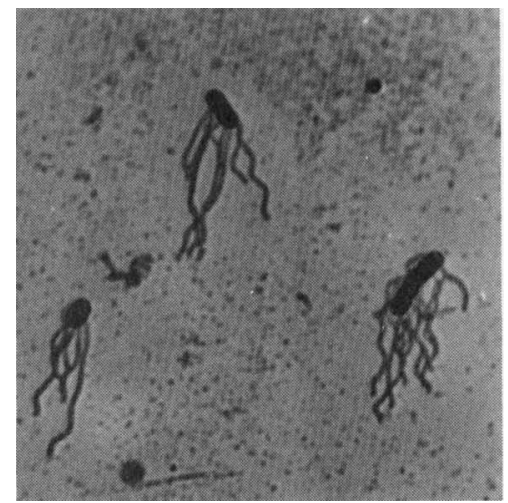

Fig. 1. Peritrichous cells of Citrobacter diversus ATCC 27156. Twenty-four-hour broth culture at 26 $C$. Staining by Leifson's method. $\times 1,200$.

Table 1. None of the isolants, herein referred to as $C$. diversus, produced hydrogen sulfide in (TSI)-agar medium in the usual period of incubation, but a few produced it in peptoneiron (PI)-agar medium. The reactions in urea agar were weak, delayed, and comparable to those exhibited by cultures of $C$. freundii. All strains formed indole, produced ornithine decarboxylase, and failed to grow in $\mathrm{KCN}$ medium (Table 1). The two that liquefied gelatin in nutrient medium did so after 26 to 30 days. The 18 isolates that failed to ferment lactose yielded positive results in tests for beta-galactosidase activity. Results obtained from the limited examination of the 24 additional strains were comparable to those listed in Table 1.

Substrates and tests that are useful for differentiation of the hydrogen sulfide-positive and -negative (TSI-agar) strains of $C$. freundii and $C$. diversus are listed in Table 2. Davis and Ewing (9) characterized 127 isolants of $C$. freundii that failed to produce detectable amounts of hydrogen sulfide in TSI-agar medium (Table 2) in the usual period of incubation. Of these, 64 produced indole (Table 3). Means for differentiation of members of this biotype and strains of $C$. diversus are given in Table 3. Finally, reactions that are of value for distinguishing strains of Enterobacter cloacae from $C$. diversus are summarized in Table 4. The data pertaining to this species are from a publication of Fife et al. (18), but they are revised since one isolate of $C$. diversus was mistakenly included among the 201 strains of E. cloacae reported upon by those investigators. Data regarding this misidentified strain were deleted from the summary of the reactions of E. cloacae (Table 4).

\section{DISCUSSION}

With few exceptions, investigators have excluded bacteria that fermented adonitol from the genus Citrobacter. For this reason, Davis 
and Ewing (8) were reluctant to admit such microorganisms to the genus although their existence was recognized. For a short time, these adonitol-positive strains were referred to as aberrant or atypical forms of E. cloacae, but this designation soon was discarded as incorrect. It now is clear that these particular adonitol-positive bacteria are members of the genus Citrobacter and should be added to that genus as the second accepted species. Comparison of the data presented in Table 2 (and in Table 13 of reference 9) indicates the relationship of these microorganisms to $C$. freundii.

Werkman and Gillen (32) described two species of Citrobacter that fermented adonitol. Cultures of the first of these $(C$. decolorans) yielded positive Voges-Proskauer tests and would not now be considered members of the genus. Werkman and Gillen's description of $C$. diversum indicated that this species was composed of indole-positive, adonitol-positive bacteria. According to Index Bergeyana (6), the name $C$. diversum (Burkey) Werkman and Gillen was validly published and is legitimate. Since this name was available and since the indole-positive, KCN-negative, adonitolpositive, ornithine-positive strains characterized herein (Table 1) yielded reactions that were similar to those described by Werkman and Gillen (32) for $C$. diversum, the authors adopted this name for these particular bacteria. The spelling of the specific epithet has been changed to diversus in accordance with current rules of nomenclature. Since the authors have been unable to locate an original strain of $C$. diversus, strain 3613-63 (ATCC 27156) is designated as the neotype (see Table 1 for description). Although strains of $C$. diversus may be categorized according to malonate utilization, no significant difference was noted between the malonate-positive and -negative forms. Therefore, these are regarded as biotypes of $C$. diversus, and further speciation on this, or any other, basis is not proposed at present.

The reactions given by strains of $C$. diversus (Table 1) do not exactly correspond to those recorded for this species by Werkman and Gillen, (32; see also Table 18, Davis and Ewing, reference 9), but the similarity is sufficient to warrant use of the name. In fact, the reactions given by the neotype strain of $C$. freundii do not correspond to the original description of $C$. freundii as well as the authors' strains of $C$. diversus correspond to the original description of that species.

The addition of $C$. diversus as a second accepted species of Citrobacter will necessitate some revision of the definitions (12) of the tribe Salmonelleae and the genus Citrobacter. Necessary emendations will be made. It is sufficient to state here that $C$. diversus belongs to the genus Citrobacter and that this species is composed of indole-positive, $\mathrm{KCN}$-negative, ornithine-positive, adonitol-positive bacteria. Hydrogen sulfide is not produced in TSI-agar medium in the usual period of incubation, but some strains yield positive results in PI-agar.

Comparison of data presented by Macierewicz (26) with data of Davis and Ewing $(8,9)$ on strains of $C$. freundii that failed to produce hydrogen sulfide in TSI-agar medium indicated that the strains described by Macierewicz probably belonged to the hydrogen sulfide-negative, indole-positive biotype of C. freundii (Table 2). Except for the weak production of hydrogen sulfide recorded by Fredriksen (19), the data recorded by this investigator were similar to those obtained by the authors with strains of $C$. diversus (Table 1). The reactions recorded for $L$. amalonatica by Young et al. (34) corresponded to those given by the hydrogen sulfide-negative, indolepositive biotype of $C$. freundii (Table 3 ), whereas those of $L$. malonatica corresponded to $C$. diversus (Table 1), except for the delayed growth in KCN medium reported by Young et al. (34). Four strains of $L$. malonatica examined by the authors failed to grow in KCN medium within 48 hours. Therefore, this discrepancy may be the result of extended incubation. The authors are of the opinion that the names proposed by Fredriksen (19) and by Young et al. (34) are later subjective synonyms of $C$. diversus (Burkey) Werkman and Gillen.

Lastly, some comment should be made regarding Citrobacter intermedius Werkman and Gillen. The original description of this species (32) stated that its members did not produce hydrogen sulfide in lead acetate medium. Because of this, the species was transferred to the genus Escherichia as Escherichia intermedia (Werkman and Gillen) Vaughn and Levine. It since has been learned $(19,25)$ that one of Werkman's original strains (ATCC 6750) of $C$. intermedius produces hydrogen sulfide in TSIand PI-agar media. Therefore, $C$. intermedius (and E. intermedia, Bergey's Manual) actually does not exist, since the only original strain of $C$. intermedius extant is a typical strain of $C$. freundii. In fact, this strain (ATCC 6750) is more typical of $C$. freundii than is the neotype (ATCC 8090) of the species (9).

\section{ACKNOWLEDGMENT}

We thank H. Hatt, American Type Culture Collection, for the photomicrograph of the flagellated cells. 


\section{LITERATURE CITED}

1. Barnes, L. A., and W. B. Cherry. 1946. A group of paracolon organisms having apparent pathogenicity. Amer. J. Public Health Nat. Health 36: 481-483.

2. Bergey, D. H., R. S. Breed, E. G. D. Murray, and A. P. Hitchens. 1939. Bergey's manual of determinative bacteriology, 5th ed. The Williams \& Wilkins Co., Baltimore.

3. Breed, R. S., E G. D. Murray, and A. P. Hitchens. 1948. Bergey's manual of determinative bacteriology, 6th ed. The Williams \& Wilkins Co., Baltimore.

4. Breed, R. S., E. G. D. Murray, and N. R. Smith. 1957. Bergey's manual of determinative bacteriology, 7 th ed. The Williams \& Wilkins Co., Baltimore.

5. Bruner, D. W., P. R. Edwards, and A. S. Hopson. 1949. The ballerup group of paracolon bacteria. $J$. Infec. Dis. 85:290-294.

6. Buchanan, R. E., J. G. Holt, and E. F. Lessel. 1966. Index bergeyana, p. 465 . The Williams \& Wilkins Co., Baltimore.

7. Carpenter, P. L., and M. Fulton. 1937. Escherichia-Aerobacter intermediates from human feces. Amer. J. Pub. Health Nat. Health 27:822-827.

8. Davis, B. R., and W. H. Ewing. 1966. The biochemical reactions of Citrobacter freundii. National Communicable Disease Center, Atlanta.

9. Davis, B. R., and W. H. Ewing. 1971. Biochemical characterization of Citrobacter freundii and Citrobacter diversus. Center for Disease Control, Atlanta.

10. Edwards, P. R., M. G. West, and D. W. Bruner. 1948. Antigenic studies of a group of paracolon bacteria (Bethesda group). J. Bacteriol. 55: 711-719.

11. Ewing, W. H. 1963. An outline of nomenclature for the family Enterobacteriaceae. Int. Bull. Bacteriol. Nomencl. Taxon. 13: 95-110.

12. Ewing, W. H. 1967. Revised definitions for the family Enterobacteriaceae, its tribes and genera. Center for Disease Control, Atlanta.

13. Ewing, W. H. 1969. Biochemical reactions of Enterobacteriaceae in commonly used tests. National Communicable Disease Center, Atlanta.

14. Ewing, W. H. 1970. Differentiation of Enterobacteriaceae by biochemical tests (revised and emended). Center for Disease Control, Atlanta.

15. Ewing, W. H., and P. R. Edwards. 1960. The principal divisions and groups of Enterobacteriaceae and their differentiation. Int. Bull. Bacteriol. Nomencl. Taxon. 10:1-12.

16. Ewing, W. H., and P. R. Edwards. 1962. The principal divisions and groups of Enterobacteriaceae and their differentiation. National Communicable Disease Center, Atlanta.

17. Ewing, W. H., and B. R. Davis. 1970. Media and tests for differentiation of Enterobacteriaceae. Center for Disease Control, Atlanta.

18. Fife, M. A., W. H. Ewing, and B. R. Davis. 1965. The biochemical reactions of the tribe Klebsielleae. National Communicable Disease Center, Atlanta.

19. Fredricksen, W. 1970. Citrobacter koseri (n. sp.). A new species within the genus Citrobacter, with a comment on the taxonomic position of Citrobacter intermedium (Werkman and Gillen). Publ. Fac. Sci. Univ. J. E. Purkynè Brno 47: 89-94.

20. Harhoff, N. 1949. Studies on bacteria of the ballerup group. Acta Pathol. Microbiol. Scand. 26:167-174.

21. Kauffmann, F. 1941. Die Bakteriologie der Salmonella-Gruppe. Munksgaard, Copenhagen.

22. Kauffmann, F., and E. M $\phi$ ller. 1940. A new type of Salmonella ( $S$. ballerup) with Vi-antigen. J. Hyg. 40:246-2 51 .

23. Kauffmann, F., and A. Petersen. 1956. The biochemical group and type differentiation of Enterobacteriacea by organic acids. Acta Pathol. Microbiol. Scand. 38:481-491.

24. Leclerc, H., and R. Buttiaux. 1965. Les Citrobacter. Ann. Inst. Pasteur (Paris) 16:67-74.

25. Lessel, E. F., et al. 1970. Catalogue of strains, American Type Culture Collection. 9th ed. Rockville, Md.

26. Macierewicz, M. 1966. A proposal of a new group (genus) of Enterobacteriaceae. Med. Dosw. Mikrobiol. 18:333-339.

27. Mфller, V. 1954. Distribution of amino acid decarboxylases in Enterobacteriaceae. Acta Pathol. Microbiol. Scand. 35:2 59-277.

28. Moran, A. B., and D. W. Bruner. 1949. Further studies on the Bethesda group of paracolon bacteria. J. Bacteriol. 58:695-700.

29. Stuart, C. A., K. M. Wheeler, R. Rustigian, and A. Zimmerman. 1943. Biochemical and antigenic relationships of the paracolon bacteria. J. Bacteriol. 45:101-119.

30. Tittsler, R. P., and L. A. Sandholzer. 1935. Studies on the Escherichia-Aerobacter intermediates. J. Bacteriol. 29:349-361.

31. Vaughn, R. H., and M. Levine. 1942 Differentiation of the "intermediate" coli-like bacteria. J. Bacteriol. 44:487-505.

32. Werkman, C. H., and G. F. Gillen. 1932. Bacteria producing trimethylene glycol. J. Bacteriol. 23: 167-182.

33. West, M. G., and P. R. Edwards. 1954. The Bethesda-ballerup group of paracolon bacteria. Public Health Service Monogr. no. 22. U. S. Govt. Printing Office, Washington, D. C.

34. Young, V. M., D. M. Kenton, B. J. Hobbs, and M. R. Moody. 1971. Levinea, a new genus of the family Enterobacteriaceae. Int. J. Syst. Bacteriol. 21:58-63. 